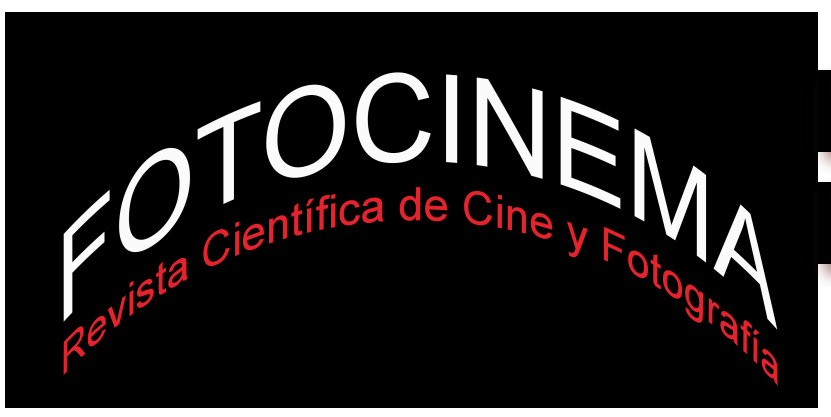

\title{
L'OBJET TROUVÉ O LA SOMBRA DEL OBJETO ENCONTRADO. DE LA FOTO AL CINE, DE LA PINTURA A MAN RAY
}

\section{L'OBJET TROUVÉ OR THE SHADOW OF THE FOUND OBJECT. FROM PHOTOGRAPHY TO CINEMA, FROM PAINTING TO MAN RAY}

\author{
Mar Marcos Molano \\ Universidad Complutense de Madrid, España \\ marmarcosmolano@gmail.com
}

\section{Resumen:}

Cuando en 1908 Man Ray descubre la fotografía de manos de Alfred Stieglitz en la 291 Gallery de Nueva York, abandona la pintura y abraza la fotografía para siempre. Algo tuvo que ver el impulso de la vanguardia europea en esta decisión, que llevó a Man Ray a la exploración de una escritura artística que transcribiera, visualmente, la escritura "automática" inspirada por el movimiento surrealista.

La dimensión técnica de la fotografía, enfatizada después por el cine, determina para el artista una línea de investigación que pronostica su encuentro, azaroso o no, con l'objet trouvé, o mejor dicho, con la sombra de ese objeto encontrado. Primero porque la fotografía y el cine no transforman el objeto, sino que utilizan la luz como tránsito hacia la imagen del mismo, que pasa a ser mirado como sombra. Y segundo, porque la fotografía y el cine en tanto que "ojos mecánicos" abrazan la idea de suplantar al sujeto creador, en aras de instituir un espectador que actúa sobre los elementos, para consumar, él mismo, la lectura simbólica del objeto artístico.

\begin{abstract}
:
In 1908, when Man Ray discovers the photography in the hands of Alfred Stieglitz at 291 Gallery in Nueva York, he quits the painting and embraces the photography forever. The momentum of the avant-garde had something to do with such decision, which brought Man Ray to the exploration of an artistic writing which visually, transcribes the "authomatic" writing inspired by the Surrealist movement.

The technical dimension of the photography, emphasized afterwards by the cinema, defines a research line for the artist which predicts his encounter, random or not, with l'objet trouvé or, better said, with the shadow of the found object. First of all, because photography and cinema do not transform the objet, but they use the light as a path towards the object's image itself, which is then seen as a shadow. Secondly, because photography and cinema as "mechanic eyes" embrace the idea of taking the place of the creator, in order to introduce an observer which acts over the elements to carry out the symbolic reading of the artistic objet.
\end{abstract}

Palabras clave:

Vanguardia; Fotografía; Cinematografía; Rayografía; Solarización; Objet trouvé

Keywords:

Vanguard; Photography; Cinematography; Rayography; Solarization; Found object 
Cómo citar: Marcos Molano, M. (2018) "L’objet trouvé o la sombra del objeto encontrado. De la foto al cine, de la pintura a Man Ray". Fotocinema. Revista científica de cine $y$ fotografía, $\mathrm{n}^{\mathrm{O}} \mathrm{XX}$, pp. 35-49. Disponible: http://www.revistas.uma.es/index.php/fotocinema/ DOI: http://dx.doi.org/10.24310/Fotocinema.2017.voi16

“... y llegó un día en que destruí la pintura y me quedé con la reproducción”. (Man Ray)

\section{Introducción}

En 1908 se produce el encuentro de Man Ray con la fotografía, concretamente con el movimiento de la Photo-Secession formalizado por Alfred Stieglitz en 1902 y consolidado con la inauguración de la 291 Gallery de Nueva York en 1905. La Photo-Secession, influida por otros movimientos que sentían la foto como arte, se aleja de la idea de la fotografía como registro de lo real e incorpora una nueva mirada sobre el medio:

El 17 de febrero de 1902, Stieglitz formó en Nueva York una sociedad para promover el reconocimiento de la fotografía pictorialista. La denominó PhotoSecession eligiendo el nombre "Secession" porque era utilizado por artistas de vanguardia en Alemania y en Austria, para señalar su independencia del oficialismo académico. (Newhall, 2002, p. 160).

Esta forma de leer lo fotográfico desde el punto de vista científico y mecánico, resultó esencial para comprender los diferentes movimientos secesionistas y su actitud frente a las Sociedades fotográficas de principios de siglo, centradas en los progresos científicos y técnicos y no en los valores artísticos inherentes al propio medio fotográfico.

El acercamiento de la foto a las artes plásticas a través del movimiento denominado "pictorialismo" produjo una mirada radicalmente renovada sobre los usos de la fotografía, llevando a los fotógrafos a la experimentación bien con nuevas técnicas como la goma bicromatada; bien con el uso de materiales como pinceles, rascadores o viejos objetivos que dejaban borrosa la imagen en los 
bordes; o efectos de desenfoque o lluvia, temblor de la cámara o el deseado efecto vaporoso en forma de flou afirmado en una luz expresiva y concluyente.

Pero las razones de este movimiento suponen una doble reacción. Por un lado, es el rechazo a ver la fotografía rozando los límites de la vulgarización acomodada en el registro de lo real y, por otro, es la comprobación de que todo lo real ya ha sido puesto en imágenes, por lo que la foto debe aprender a expresar lo real de otro modo:

Por esa época habían aparecido las primeras placas pancromáticas y se podía fotografiar en blanco y negro, conservando los valores de los colores. Estudié con aplicación y me convertí en un experto. Lo que más me interesaba era la gente, especialmente los rostros. En lugar de pintar personas, comencé a fotografiarlas, y ya no quise pintar retratos. $\mathrm{O}$ bien, si pintaba un retrato, ya no me interesaba el parecido. Finalmente, decidí que no había comparación entre ambas cosas, fotografía y pintura. Pinto lo que no puede ser fotografiado, algo surgido de la imaginación, o un sueño, o un impulso subconsciente. Fotografío las cosas que no quiero pintar, cosas que ya existen. Me había cansado de la pintura (Ray en Hill y Cooper, 2001, p. 17).

Pero el movimiento pictorialista suscribió en sí mismo la nostalgia por la pintura, lo que provocó una necesaria revisión del universo fotográfico hasta tocar el polo opuesto: la Fotografía Pura, compromiso único e ineludible de documentar la realidad, "que los fotógrafos hagan fotos que parezcan fotos en lugar de pinturas” tal como reclamaba Sadakichi Hartmann en 1904 (Newhall, 2002, 167), a través de un encuadre preciso, luz natural y toma directa, condenando las copias a la goma, el proceso de la glicerina o la manipulación sobre negativos y copias.

Y cuando copiar la realidad resultó ya un discurso superado, el periodo de entreguerras revela una fotografía liberada del reduccionismo técnico e integrada plenamente en las vanguardias artísticas, precisamente porque los años veinte tuvieron la necesidad teórica y práctica "de instituir una nueva cultura (...) capaz de integrar los medios de expresión fundados en la técnica” (Durozoi, 2007, p. 240). La descompartimentación de las prácticas artísticas permitió hablar de un fecundo diálogo entre la pintura y la fotografía capaz de 
restituir el "impulso vital" necesario del arte, tanto sobre el lienzo, como sobre la película fotográfica primero y la cinematográfica después:

Así que comencé a pintar sin pinceles, o sin tela, o sin paleta. Comencé a pintar con aerógrafo, con soplete, con aire comprimido. Fue un maravilloso alivio pintar un cuadro sin tocar la tela. Pintaba prácticamente en tres dimensiones porque, con la pistola de aire, si quería una fina línea, dibujaba cerca de la superficie, y si quería modelar una sombra, me movía en una tercera dimensión (Ray en Hill y Cooper, 2001, p. 17).

\section{Marco teórico y metodología}

Las vanguardias del siglo XX mostraron una enorme fascinación por la dimensión técnica de la fotografía y del cine, así como de sus efectos de velocidad, ubicuidad e impacto. Más concretamente, la vanguardia soviética reivindicó las posibilidades técnicas del medio y descubrió al mundo del arte las nuevas relaciones sinestésicas que ofrecía la tecnología fílmica emergente. Es el Cine Puro de Dziga Vertov, que al igual que la Foto Pura de Strand, mantiene su compromiso con la realidad, en este caso porque la cámara es un instrumento capaz de captar las cosas como realmente son, mejor que el propio ojo humano.

Es la lente misma de la cámara la que organiza el caos visual presente en el mundo, esa misma lente que representa los ojos de un observador quien, implícito en la obra, ve la acción sin la intervención de los pensamientos o creencias del cineasta. El cine como “ojo mecánico” se acompaña de la idea de remplazar al sujeto creador, mientras el montaje de las imágenes revela lógicas experienciales de carácter expresivo que logran un "efecto poético" con la intención de canalizar la experiencia del espectador. Obsesionado por el movimiento y la velocidad, el trabajo de Vertov es una alegoría de su propia relación con el cine, heredera de la fascinación por la tecnología propia del futurismo y el constructivismo.

Sin embargo, escribe Walter Benjamin, el futurismo es un intento insuficiente del arte por tener en cuenta la intromisión de los aparatos en la realidad (Benjamin, 1934): 
Es importante que esta expresión señale, más allá de la figuración o de la recuperación de mecanismos y de máquinas en la pintura, la novedad de los aparatos de la técnica, de la mecánica, como modelos, con sus correlatos de exactitud (...) que no se quedan en los efectos sino que van también al automatismo... (Albera, 2009, p. 70).

Desde esta argumentación, la obra pictórica se transforma en un "aparato" (Déotte, 2012) perfeccionado, que proyecta la pintura y ausenta al artista, atomizando de este modo el dispositivo y precisando de la actividad del espectador para actuar sobre los elementos pictóricos, provocando una lectura simbólica ejecutada como actividad perceptiva. El desarrollo de esta actividad por parte del espectador liberó al artista del enfoque mimético. Ello permitió que el movimiento dadaísta se posicionara visiblemente del lado del objeto, al punto de que los aparatos fotográfico y cinematográfico suplantaron al pincel: "tomar un par de tijeras recortar aquello que necesitamos en las pinturas, las reproducciones fotográficas de los objetos, incluso tomar a los propios objetos” (Herzfelde en Albera, 2009, p. 73).

El automatismo, los aparatos mecánicos o la impresión azarosa de placas y películas, en las que cuerpos y materias no sufren transformación física pues tan sólo utilizan la luz como tránsito hacia su representación, en palabras de Breton, esos aparatos mecánicos que no se "hipnotizan" con el dibujo que diseñan, desintegran el concepto de autor como «artista-creador» y preconiza la idea de un «autor-registrador» enfrentado a un «espectador-operador» que se apropia de la obra con una mirada de activa valoración, de lo automático y de lo azaroso.

\subsection{Hacia la construcción de un Cine Absoluto}

Los orígenes del cinematógrafo conviven en un contexto de redefinición del mundo artístico, tanto es así, que la vanguardia en el cine procedía de diferentes movimientos artísticos que se apropiaron del mismo, en busca de nuevas salidas expresivas gracias a su novedoso sistema de registro. En este punto, movimientos como el futurismo se embriagaron de cine, dado su gusto por la innovación tecnológica y por el deseo de captar el movimiento y la velocidad: el 
cine como continuación de la pintura, un gran lienzo que se prolonga en el tiempo.

Un arte visual que se distingue de la pintura por el hecho de que se desarrolla en el tiempo (como la música) y porque el punto clave de lo artístico no consiste (como en los cuadros) en reducir un proceso a un momento (real o formal) sino justamente en el desarrollo cronológico de lo formal (Schobert, 1989, pp. 102103).

Pero no sólo en el futurismo, el enfoque del Cine Absoluto enraizó profundamente con la actitud dadaísta en la búsqueda de los elementos puros del cinematógrafo - movimiento, simultaneidad, composición, desplazamiento, ritmo...-, que también interesaron a surrealistas y cubistas. De este modo, la deriva estética del cine consistió en superar la reproducción, como años antes lo hiciera la fotografía, en este caso mediante lo "cinético-visual", llegando así al manejo libre de los medios considerados netamente cinematográficos: orquestación del movimiento en ritmos visuales; representación de los objetos en movimiento, sometidos a cambiantes condiciones de luz; distorsiones del objeto y su re-creación desde posiciones estrictamente cinematográficas; desfiguración del objeto para, con ayuda de la luz, volver a configurarlo como material poético y constructivo... y es que "los objetos, arrancados de su nexo cotidiano y colocados en correlaciones nuevas, transmiten experiencias inusitadas desconocidas hasta ahora” (Richter, 1952), incluso el ritmo visual se transforma en un principio puro.

A ello se unió la necesidad de un cine al margen de la narración, emancipado del argumento convencional y de la cronología de los hechos, que fulmina la causa-efecto y se sitúa más allá del texto literario, entre la música y la pintura. El propio devenir del arte moderno llevó a los artistas de vanguardia a instalarse en el cine: la organización y orquestación de la forma, del color y la luz, la dinámica del movimiento, la simultaneidad..., eran aspectos contra los que chocaron cubistas y futuristas y, aún antes, impresionistas.

Pareciera que el Cine Absoluto fuera un cine realizado por pintores, que utilizaban de manera artesanal procedimientos técnicos de filmación privilegiando la luz como forma de individualizar las formas en una dimensión 
temporal. Su logro residió en el juego de contrastes: imágenes en libertad, asociaciones rítmico-figurativas, collage de procedimientos... que, mutados en sinfonía visual, precisaron de un espectador capaz de aprehender la belleza sin preocuparse por su anclaje de significado.

\section{Man Ray y la imagen pura del objet trouvé}

...ante mis ojos comenzó a formarse una imagen, no una simple silueta de los objetos, sino como si fuera una fotografía, pero distorsionada y con la refracción producida por el cristal. (Ray en Jacob, 2007, p. 18-19).

Cuando entre 1921 y 1922 Man Ray trabajaba en su cuarto oscuro, colocó unos objetos de cristal sobre una hoja de papel fotográfico emulsionado de químico revelador. Al encender la luz, la huella luminosa de los objetos se había precipitado sobre el papel. Es así como ante los ojos de Man Ray aparece una imagen que le devuelve la forma del objeto interpuesto, pero no como reproducción literal sino como trazo disociado del objeto mismo.

\subsection{De la foto $y$ de la pintura: interferencias}

Este procedimiento bautizado como Rayografía, resultó ser un singular objeto que escapaba a toda definición, en tanto que ejercicio sutilmente intelectual y perverso. “Tras desembarazarse de la cámara fotográfica, la imagen se convirtió en algo puro, en una imagen pensante. No se parecía en nada al molde que la había originado" (Janus, 1983, p.49). Man Ray descubre la sombra del objeto encontrado y, la Rayografía pasa a ser, precisamente, ese objet trouvé del arte fotográfico, como objeto modificado, interpretado y adaptado, que descontextualiza la cotidianeidad del objeto que soporta.

El hecho de poder prescindir de la cámara supuso para Man Ray una gran liberación, como años antes, supusiera la sustitución del pincel por la pistola de aire. En este sentido, la foto que practica Man Ray se aproxima a su forma de entender la pintura que, en la misma preocupación de sus contemporáneos, pasa por transformar la figuración tradicional (Durafour, 2010). A ello se añade el carácter único de cada rayografía, extraída por contacto del objeto mismo sobre la superficie de la imagen donde finalmente devendrá obra artística. Man 
Ray resuelve su proceso creativo trabajando básicamente con el objeto - no hay pincel en su pintura, ni cámara fotográfica en su rayografía, ni cámara de cine en los filmes donde introduce la técnica rayográfica-. Hay un compromiso del autor por hacer de la creación artística un acto esencialmente mental, una condición del espíritu: separando la imagen de su figuración mimética, ésta va al encuentro de un objeto poético que se deshace de su peso, de su volumen, de su materialidad y de sus usos ordinarios (F1), para convertirse en luz. Y en sombra.

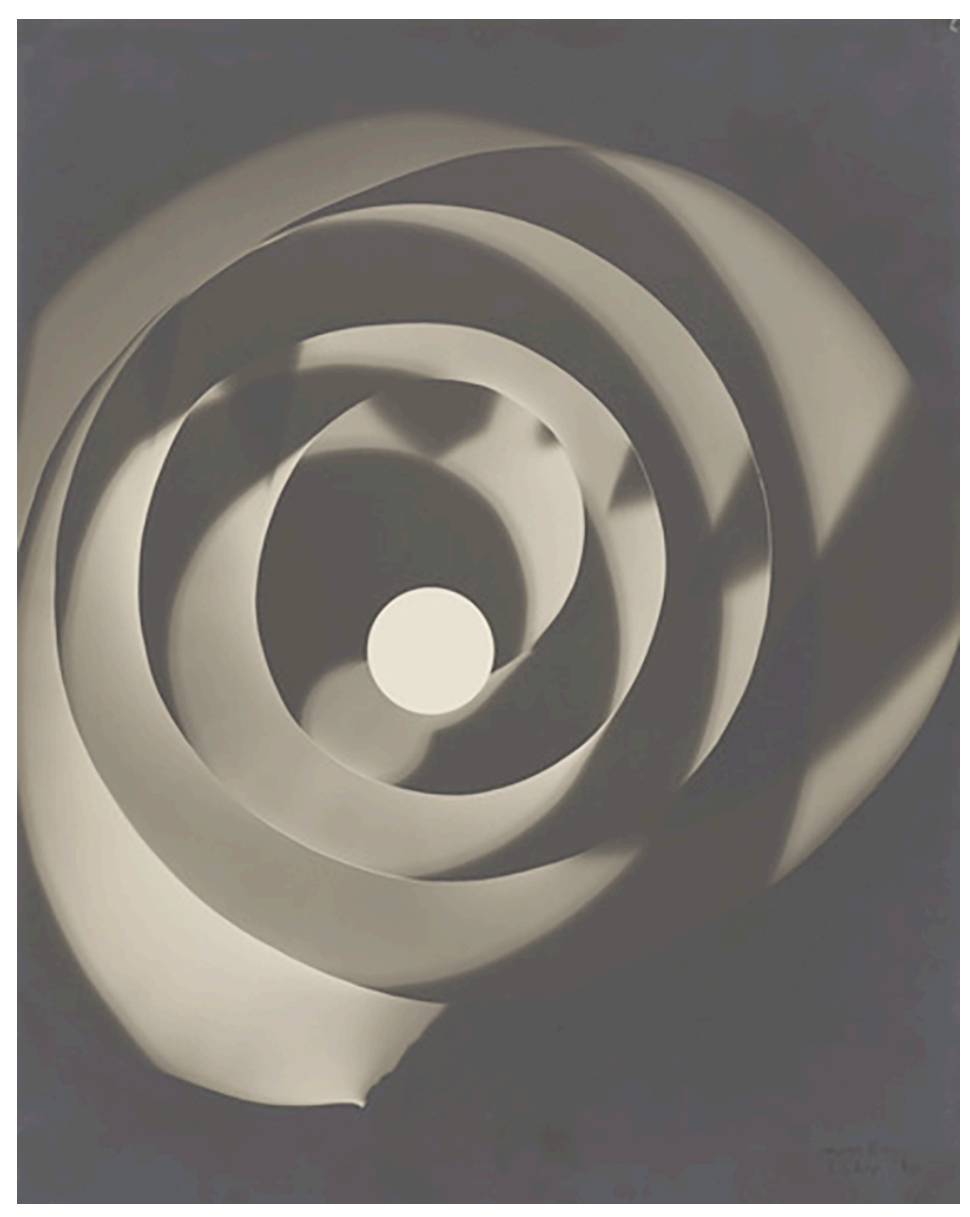

F1. Ribbons, París, 1924. Rayografía de Man Ray

Si bien la Rayografía no fue una invención de Man Ray puesto que el procedimiento de imagen por contacto, sin el uso de la cámara oscura, constituye el fundamento del calotipo (F2), los dibujos fotogénicos de Fox Talbot no tenían otra intención que utilizarse "para la plasmación de la arquitectura, la escultura y bajorrelieves y de la naturaleza” (Marcos, 2006, 
p.185). Cien años después, liberada ya la fotografía de la literalidad de la reproducción, Man Ray hace del procedimiento rayográfico la imagen de la ensoñación fantástica, transcripción visual del autor de la llamada "escritura automática” inconsciente y sin censuras, impulsada por el grupo surrealista e incluida en su propio seudónimo: "en el rayograph va implícito el nombre de su inventor, ya que Ray significa «rayo» y, Man Ray, como escribió Breton, quiere decir le capteur de soleil" (Janus, 1983, p.4).

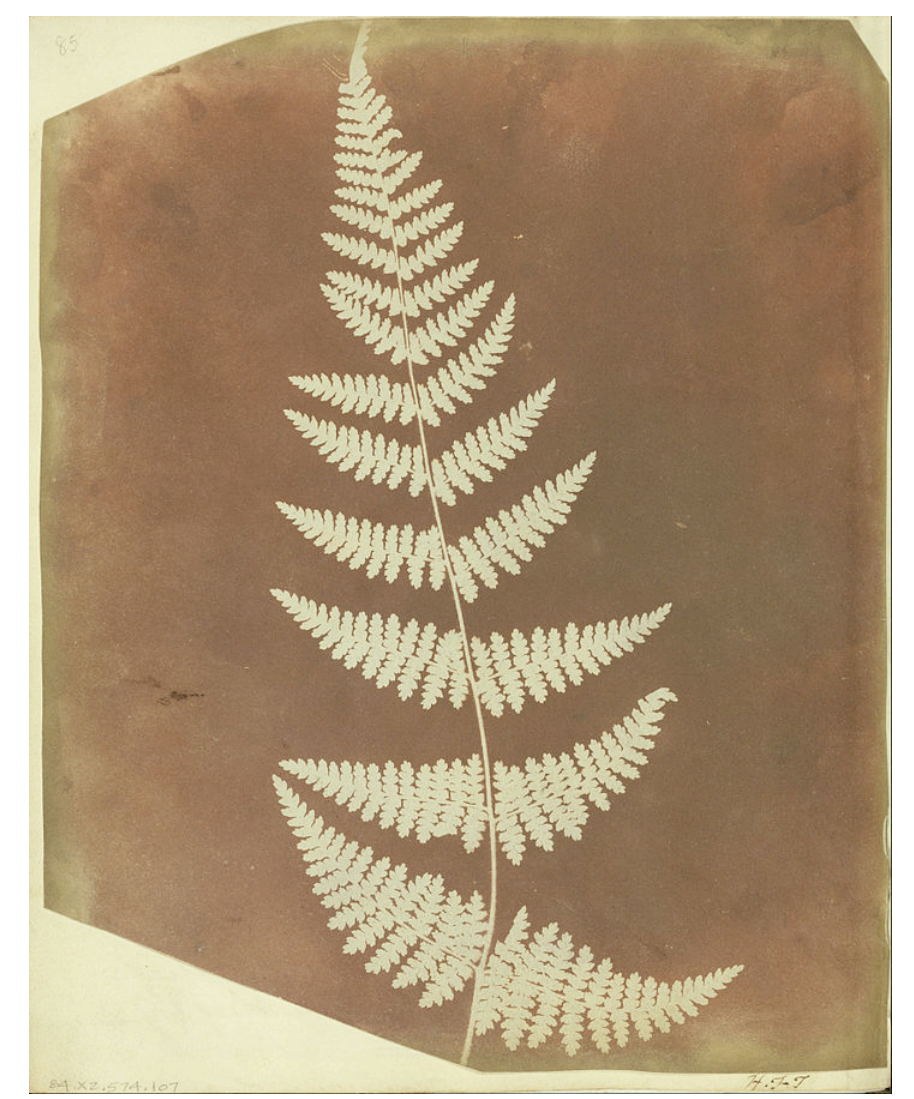

F2. Buckler Fern, British, 1839. Calotipo de Henry Fox Talbot

Si la rayografía es el ready made, resultado del tropiezo azaroso de Man Ray con el objet trouvé, la técnica de la Solarización no vino sino a reafirmar la fascinación del artista por encontrar el objeto artístico explorando las sombras. Man Ray se apropió del descubrimiento de Lee Miller elevando la técnica a posibilidad artística: el efecto de solarización, producido cuando un positivo se expone a la luz durante su revelado, recrea una imagen de ensoñación, privada 
de realidad, al revertir los tonos en las áreas no expuestas del negativo. Se trataba de un rayo de luz solar alrededor del perfil de las figuras.

La solarización abre para Man Ray nuevas posibilidades en el uso de objetos artísticos introduciendo en este juego dadaísta la figura humana (F3): muchos de los retratos realizados combinan el efecto de solarización con pantallas texturizadas, procedimientos para disminuir la nitidez, virados y modificaciones en el contraste..., Man Ray mezclaba los procedimientos de forma espontánea, logrando un efecto de flash luminoso. La imagen solarizada resultante, devuelve la efigie del doble, y refuerza la delineación del objet trouvé. Pero la solarización, aunque fuese un procedimiento netamente fotográfico, no parecía perceptivamente fotografía, ni pintura..., se acusó a Man Ray de obtener esos efectos precisamente a través del dibujo.

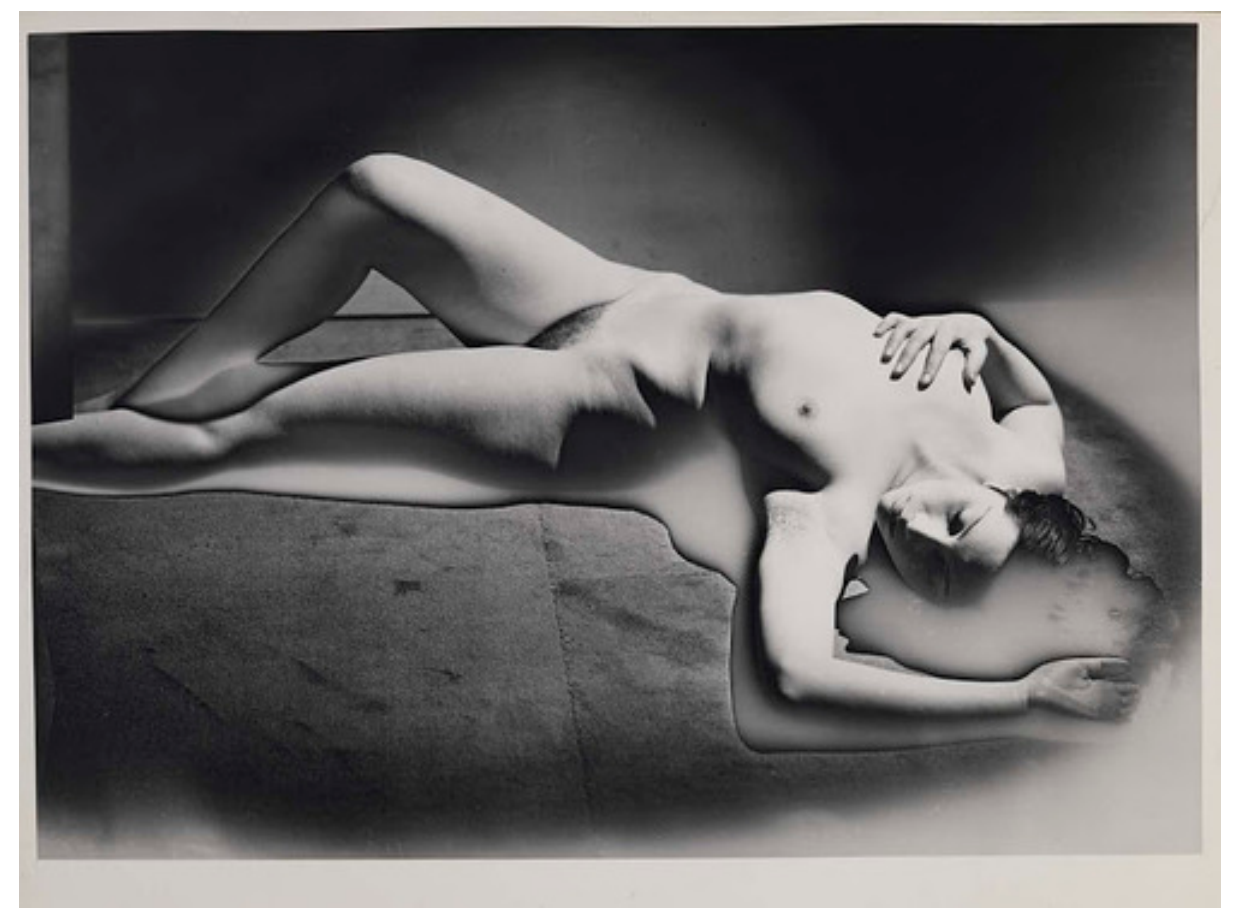

F3. Primat de la matière sur la pensée, París, 1929. Solarización de Man Ray

Cuando en 1936 Man Ray publicó "Fotografía no es arte”, pudo interpretarse como una declaración del artista de su visión de la foto -más técnica que artística-, de su frustración ante el medio o, podría entenderse como una necesidad de investigar un nuevo lenguaje para todo lo fotográfico a partir de 
sus experiencias de laboratorio. Precisamente su aproximación al cine se realiza desde esta necesidad de experimentación hasta conseguir cierta madurez truncada.

\subsection{De la foto $y$ del cine: interrelaciones}

Me procuré un rollo de película de unos treinta metros, me instalé en mi cuarto oscuro donde corté la película en pequeñas bandas que sujeté con alfileres. Salpimenté algunas bandas, sobre otras puse alfileres al azar. Los expuse a la luz blanca unos segundos, como solía hacer para las rayografías inanimadas (...). Al día siguiente examiné mi trabajo (...) las imágenes no estaban separadas como en un filme convencional... (Ray en Hass, 1986, p. 162-163).

Man Ray quiso ver cómo se transfiguraban sus imágenes merced al movimiento y trasladó sus investigaciones de laboratorio sobre la imagen fija al cine, haciendo de éste el insólito escenario de la rayografía. Su filme Le retour à la raison (1923), no es más que una reflexión personal sobre el dispositivo cinematográfico y sus conexiones con la fotografía en su dimensión temporal. El filme se organiza desde un orden caótico intencionado, juntando material filmado con una secuencia de experimentos fotográficos. Pero Man Ray no restituye el movimiento, deja que el objeto inanimado se desplace en el tiempo del celuloide impresionado por contacto que, lejos de ser la sombra y aún el doble, como sí lo era en la rayografía y aún en la solarización, abandona al objeto, sometiéndolo a un ritmo temporal que no tiene más deriva que el delirio óptico.

Quizá el único interés de esta pieza resida en el hecho de tratar los desplazamientos entre fotografía y cine, explorando las calidades de la luz (en el tiempo) y rompiendo los límites de esa forma de representación hacia un cine casual y fortuito, pese a que la espontaneidad no sea concepto estrictamente cinematográfico, y la técnica del cine lleve implícitas ciertas lógicas constructivas en su necesaria definición como imagen secuencial.

Sin embargo, esta primera película precipitó a Man Ray hacia una elaboración fílmica que investiga sobre su propio fundamento cinematográfico en la comprobación de que cine y fotografía tienen muchas confluencias, pero no es la materialidad de la imagen la más importante de ellas: si la rayografía 
funciona como objet trouvé de lo fotográfico, el cine también encuentra su objet trouvé pero en la representación simbólica del objeto, no en el objeto fílmico como materialidad, pues, a diferencia de la fotografía, esta materialidad se desvanece en el tiempo de la proyección:

La proyección no duraría más de tres minutos. Pasara lo que pasara, pensé, se habrá acabado antes de que los asistentes tengan tiempo de reaccionar. En el programa figuraban otras presentaciones destinadas a probar la paciencia de los espectadores, que era en definitiva, el fin principal de los dadaístas. (Ray en Hass, 1986, p. 163).

Esta fascinación por la recreación simbólica del objet trouvé, es el elemento en torno al cual gira la concepción de su filme titulado L'étoile de mer (1928). Man Ray abandona la escritura automática dadaísta y traduce, en una puesta en escena orquestada desde una supuesta casualidad - el encuentro de una mujer y un hombre-, el tejido causal del texto: la relación amorosa, el componente erótico, el amour fou del surrealismo. El resultado es un filme que hace chocar las imágenes con las palabras derivadas del poema del que surge, “...la técnica como instrumento que modifica la condición de visibilidad de lo real y el cinematógrafo en su función liberadora del sentido de la vista... (Ledo, 2005, p.79), perpetuando la presencia de un espectador obligado a tejer las relaciones entre los elementos visuales y literarios en la cadena secuencial, tal como los impone el cineasta al poeta: "Poème de Robert Desnos tel que l'a vu Man Ray”.

Para fotografiar las escenas, Man Ray se sirve de gelatinas que, colocadas sobre la lente, provocan una visión distorsionada de lo real. Lo onírico se apodera de la representación visual, en tanto que el texto escrito presenta la aventura romántica que se inicia en lo real y emigra al sueño del espectador, voyeur accidental del encuentro sexual, entre las rendijas viscosas de sus luces y sus contrastes.

Dentro del plano, pero oculto entre los mecanismos de registro, la mujer se desviste, mas el encuentro amoroso no se produce. Los ojos de ella se topan con los del espectador, el personaje masculino entra en el cuadro y tras él, aparece el objet trouvé, a modo de pisapapeles sobre las páginas amontonadas de unos periódicos: una estrella de mar en un tubo de vidrio. Y mientras exploran ese 
objeto encontrado (F.4), la relación sexual no ocurrida, ocurre, precisamente dentro del ready made. Una sexualidad contenida, casi masturbadora, en la que la estrella se acomoda en el interior del cilindro de cristal. Él se deja fascinar, lo observa a contraluz, en plano detalle, desde diferentes ángulos, en su rugosa formación, en su textura luminosa y en su movimiento. Por su parte, ella se mueve dentro de él, y se relaja dentro de él.

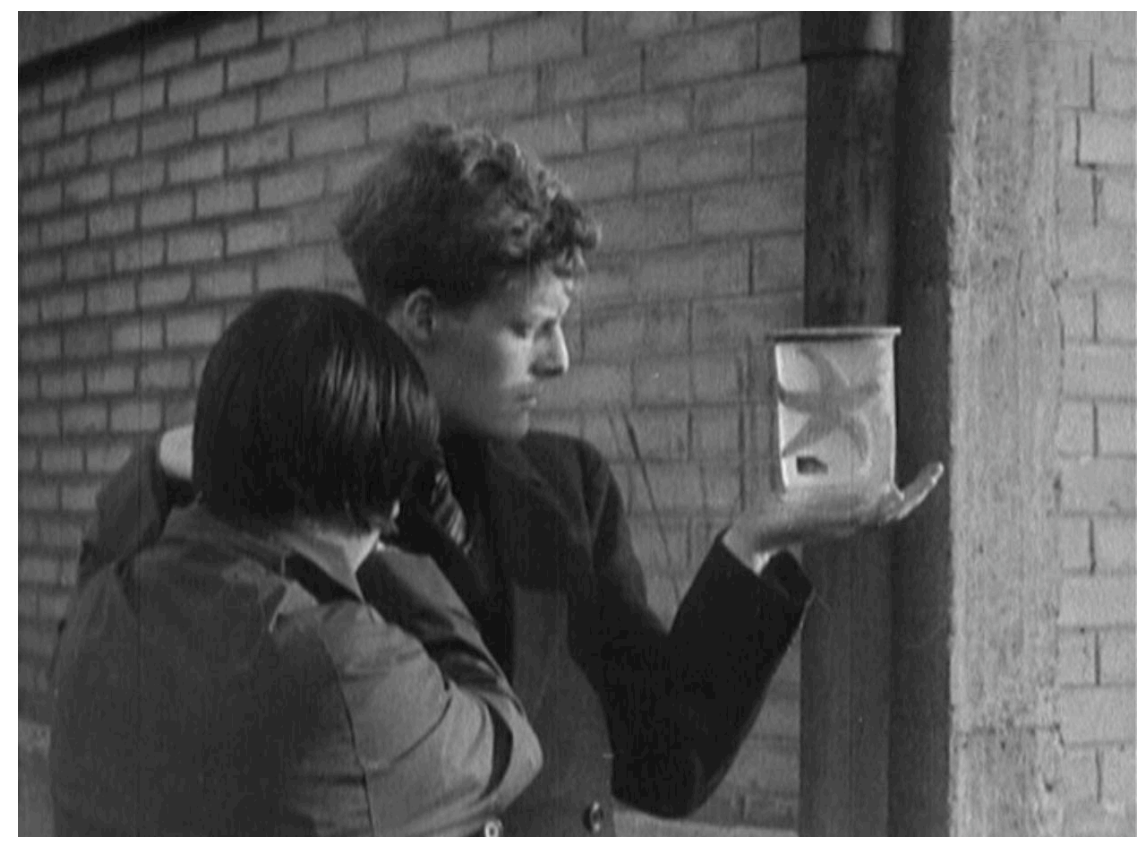

F4. L'etoile de mer, París, 1928. Fotograma

Después de un montaje expresivo, de ritmo mecánico, puramente óptico, ella vuelve a nuestra mirada desde un plano casi cenital de extraordinaria belleza. La estrella está fuera del cilindro, ella pisa el texto más allá de la estrella, es el triunfo del amour fou surrealista. "Qu'elle était belle, qu'elle est belle”. Mientras él se aferra al objet trouvé con la estrella de mar dentro del cilindro, ella rompe el cristal y recupera su estrella. Para ofrecérsela a otro.

No es sólo el contenido erótico del objeto cilíndrico que contiene la estrella el interés del filme, por encima de esta lectura individual, se eleva la presencia de ese objeto como ready made, al incitar al espectador a interpretar y depositar en ese objeto múltiples significados. El objeto es cuestionado tanto desde la diégesis como fuera de ella y, de este modo, Man Ray insta al observador a ir más allá de la apariencia en busca de su reflexión. 
El objet trouvé del filme no es obra de Man Ray en su fisicidad pero sí en su proceso mental y espiritual. Ese mismo objeto que invita al espectador a contemplar su mundo con otros ojos y sobre todo, a encontrar el placer estético en los objetos cotidianos:

El objeto de Man Ray no es sólo un ready made, sino casi siempre un ready made modificado; emplea también un objeto al lado de otro sin ninguna relación entre sí, pero cuyo acoplamiento sugiere inquietantes, secretas, irracionales analogías (Argan, 1998, p. 625).

\section{Conclusión: de la obra y de la reproducción}

Man Ray realizó ejercicios audiovisuales posteriores pero siempre volvía a reintegrarse dentro de los límites de la fotografía, desde la cual consumó sus apuestas más valientes. A través de la fotografía comprendió que podía acercarse al secreto que guardan los objetos. Y si los inicios de su carrera son una aproximación a la foto a través de la reproducción de sus pinturas y de las pinturas de otros, el final de su carrera vuelva a esta concepción artística reproduciendo sus primeras obras como litografías, y trabajando el concepto de la reproducción en serie de sus objetos únicos.

Esta concepción resulta muy interesante precisamente en el trabajo de Man Ray puesto que siempre tuvo una actitud de distancia frente al aura de los objetos, pues el objeto y su reproducción comulgan juntos: "la inspiración que daba nacimiento a un objeto único, afirmaba, quedaba corroborada por la reproducción de éste, al tiempo que su reproducción se convertía en vehículo difusor de la idea inspiradora" (Jacob, 2007, p. 33).

Desde este punto de vista, la aportación de Man Ray, interesado por las ideas que motivan la creación de la obra, pasa por defender que la reproducción posee un valor igual al de sus obras acabadas. Es el valor de las ideas por encima del resultado: la idea para una obra de arte tiene más importancia que el objeto artístico resultante. 


\section{Referencias bibliográficas}

Albera, F. (2009). La vanguardia en el cine. Buenos Aires: Manantial.

Argan, G.C. (1998). El arte moderno. Del iluminismo a los movimientos contemporáneos. Madrid: Akal.

Benjamin, W. (1971). L' homme, le langage et la culture. Paris: DenoëlGonthier coll. Essai 1, 1922-1934

Déotte, J.L. (2012). ¿Qué es un aparato estético?: Benjamin, Lyotard, Ranciere. Santiago de Chile: Metales pesados.

Durafour, J.M. (2010). Man Ray: voir le cinéma en peinture. En Ligeia n ${ }^{\circ}$ 97100, (pp. 62-73)

Durozoi, G. (2007). Diccionario del Arte del Siglo XX. Madrid: Akal.

Haas, P. (1986). Cinéma Integral. De la peinture au cinéma dans les années vingt. París: Transédition.

Hill, P. y Cooper, T. (2001). Diálogo con la fotografía. Barcelona: Gustavo Gili.

Jacob, J.P. (2007). Despreocupado pero no indiferente. Catálogo de la Exposición, (pp.13-39). Madrid: La Fábrica.

Janus. (1983). Man Ray, un fotógrafo anarquista. En Los Grandes Fotográfos, (pp. 4-10). Barcelona: Orbis.

Ledo, M. (2005). Cine de fotógrafos. Barcelona: Gustavo Gili Fotografía.

Marcos, M. y otros (2006). La cultura de la imagen. Madrid: Fragua.

Newhall, B. (2002), Historia de la fotografía. Barcelona: Gustavo Gili.

Schobert, W. (1989). El cine alemán de vanguardia de los años veinte. München: Goethe-Institut. 